\title{
SOLUÇÃO DE PROBLEMAS EM UMA EMERGÊNCIA HOSPITALAR: AVÁLIAÇÃO DOS MÉTODOS A3 E ANÁLISE DE CAUSA RAIZ1
}

\section{PROBLEM SOLVING AT AN EMERGENCY ROOM: EVALUATING A3 AND ROOT CAUSE ANALYSIS METHODS}

\author{
Fábio Rodrigues Priori E-mail: fabiopriori@gmail.com \\ Tarcisio Abreu Saurin* E-mail: saurin@ufrgs.br \\ *Universidade Federal do Rio Grande do Sul (UFRGS), Porto Alegre, RS
}

\begin{abstract}
Resumo: Dada a importância da solução de problemas para a manutenção da qualidade em um processo, esse trabalho objetiva avaliar dois métodos de melhoria contínua amplamente utilizados para solução de problemas: o $A 3$ e a Análise de Causa Raiz (RCA). Para esse fim, as duas abordagens foram aplicadas no mesmo processo, de prescrição e medicação, da emergência de um hospital universitário. Os resultados das aplicações foram verificados de acordo com os critérios: número de ações de melhoria propostas, dificuldade de implementação, a abrangência das ações entre as unidades do hospital, o tempo necessário para aplicação dos métodos, o número de envolvidos e a necessidade de capacitação da equipe. Os resultados demonstram que, no contexto avaliado, o método RCA resultou em um número maior de ações de melhoria sugeridas, as quais tiveram, em média, melhores avaliações nos critérios dificuldade de implementação e abrangência entre as unidades.
\end{abstract}

Palavras-chave: Melhoria contínua. A3. RCA. Solução de problemas. Hospital. Erros de medicação. Prescrição. Emergência.

Abstract: Considering the importance of problem solving for process quality maintenance, this work has the objective to evaluate two continuous improvement methods commonly used for problem solving: $\mathrm{A} 3$ and Root Cause Analysis (RCA). To achieve that, the two methods were applied in the same process, of prescription and medication, at the emergency room of an university hospital. The results were verified accordingly to the following criteria: the total number of improvement actions proposed, implementation difficulty, replication possibility along the departments of the hospital, the time required to apply the method, the number of people involved and the need of training for the team. Results show that, in the evaluated context, RCA resulted in more improvement actions, which had, on average, better evaluation in the criteria of implementation difficulty and replication possibility.

Keywords: Continuous improvement. A3. RCA. Problem solving. Hospital. Medication errors. Prescription. Emergency.

\section{INTRODUÇÃO}

Segundo Paim et al. (2012), apesar da crescente conscientização sobre a importância da qualidade da atenção à saúde no Brasil, ainda é necessário avançar

\footnotetext{
1 Artigo resultante de dissertação de mestrado submetida ao Programa de Pós Graduação em Engenharia de Produção da Universidade Federal do Rio Grande do Sul em outubro de 2017.
} 
muito para assegurar padrões consistentemente elevados. Nesse sentido, iniciativas de melhoria e reestruturação dos processos hospitalares têm sido crescentemente usadas no setor.

Enquanto métodos individuais aprimoram os processos em vários aspectos, cada um tem pontos fortes e fracos, sendo que uma combinação de metodologias pode resultar em um programa de melhoria contínua mais consistente. Além disso, determinados métodos tendem a ser mais adequados para lidar com certos problemas (FONSECA; MIYAKE, 2006). Diversos métodos analíticos são utilizados no âmbito da melhoria contínua para solução de problemas. Dentre os métodos mais conhecidos, dois são discutidos neste artigo: o processo de gerenciamento A3 e a Análise de Causa Raiz. Ambos são métodos de solução de problemas com diferentes enfoques e requisitos, amplamente utilizados nos mais diversos setores empresarias.

O método A3 é um guia sistematizado de solução de problemas, por meio de consenso entre as partes afetadas, que documenta os problemas principais de um processo e as propostas de melhorias (SOBEK; JIMMERSON, 2006). A Análise de Causa Raiz, ou RCA, abreviação de Root Cause Analysis, é um método "desenvolvido para auxiliar a identificar não apenas o que e como um evento ocorreu, mas também por que ele ocorreu", permitindo a investigação e classificação das causas raízes de um evento (ROONEY, 2004). A classificação das causas possibilita identificar onde é possível intervir de uma maneira responsável, de forma a impedir a recorrência do problema (FINLOW-BATES et al., 2000).

O método escolhido pode conter limitações para o tipo de problema abordado, ou mesmo necessitar de recursos dos quais a empresa não dispõe no momento, adiando a solução indefinidamente e resultando em insatisfação dos clientes impactados. Pode-se citar o exemplo da empresa canadense Bombardier que, após investir em uma metodologia individual de melhoria contínua baseada em análise de causa raiz, concluiu que seriam necessárias outras abordagens para alcançar alguns dos resultados que almejavam, assim como a American Express, Merck e Motorola chegaram a conclusões similares (HAMMER, 2002).

Fonseca (2006) sugere que é necessário desenvolver critérios e recomendações que facilitem a seleção e aplicação do método mais pertinente para se buscar soluções ou melhorias nas organizações, dependendo das circunstâncias 
identificadas. Esse trabalho objetiva realizar uma análise da aplicação de dois métodos de melhoria contínua voltados para solução de problemas, A3 e RCA, em um ambiente hospitalar, indicando diretrizes para a seleção do método mais adequado em determinada situação. Os métodos serão aplicados em problemas de medicação, relacionados à prescrição de medicamentos observada em um hospital universitário.

\section{REFERENCIAL TEÓRICO}

\subsection{Erros de Medicação e Prescrição}

Novaretti (2014) define erro de medicação como todo incidente que possa ocorrer durante as três principais fases do processo de medicação, ou seja, a prescrição do medicamento pelo médico, a farmácia dispensar o medicamento e a enfermagem administrar o medicamento no paciente. Nota-se na literatura que erros de medicação são identificados e que suas frequências variam de um estudo para outro, visto que o processo de medicação é diferente em cada instituição e possui características próprias que precisam ser identificadas pelos pesquisadores para auxiliar na análise dos erros (TEIXEIRA E CASSIANI, 2010).

Hartel et al. (2011) verificaram, ao analisar um hospital universitário, que uma alta taxa de erros de medicamentos está relacionada à erros de prescrição, envolvendo principalmente erros na transcrição de prescrições manuais. Tully et al. (2009) observaram que erros de prescrição estão associados à múltiplas causas potenciais e condições favoráveis à falha, normalmente agindo em conjunto. Segundo Teixeira e Cassiani (2010), erros de prescrição são ocorrências comuns, sendo a equipe de enfermagem, com conhecimento adequado sobre os medicamentos, uma barreira importante no sistema de medicação para interceptálos, além da prescrição eletrônica e a presença de um farmacêutico clínico serem estratégias para evitar esse tipo de erro. Pasin (2015) entende que a falta de uma prescrição vigente atinge negativamente a qualidade do serviço prestado, aumentando a urgência da equipe na realização das tarefas e prejudicando a humanidade e empatia no atendimento ao paciente. 
Teixeira e Cassiani (2014) verificaram que a equipe de enfermagem está inserida no cenário no qual erros de medicação ocorrem e, muitas vezes, no Brasil, a causa da ocorrência desses tipos de incidentes relacionados à segurança dos pacientes incide sobre esta equipe, apesar de se ter conhecimento de que além de falhas individuais, também, falhas ambientais, estruturais e processos mal elaborados, contribuem para isto; essa situação acaba por gerar insegurança quanto ao registro de desvios, que podem acabar não sendo notificados por medo de punição. Entende-se que o aumento no número de notificações de erro de medicação não evidencia piora do serviço, mas sim, adesão do profissional à assistência segura ao paciente, no que tange a informar os eventos adversos ocorridos (NOVARETTI, 2014). É necessário que os gestores e administradores encorajem os profissionais a notificar a ocorrência de incidentes relacionados à segurança do paciente, focando a cultura de segurança e a não punição, pois frequentemente $O$ medo da punição envolve a não notificação dos incidentes ocorridos (TEIXEIRA; CASSIANI, 2014).

A complexidade das causas dos erros de prescrição implica que soluções simplistas ou paliativas, que atacam uma única causa, provavelmente terão eficácia limitada (TULLY et al., 2009). A ausência de prescrição médica válida no momento de administração do medicamento resulta na necessidade de reorganização das atividades assistenciais e do processo de trabalho, atingindo negativamente a qualidade do serviço prestado ao paciente (PASIN, 2015). Para Wu et al. (2007), se eventos são comuns em diferentes hospitais, as ações corretivas deveriam ser planejadas no sistema de saúde, não no nível hospitalar, pois sem o esforço colaborativo de todos os envolvidos para a solução de um problema, os hospitais podem abordar o problema apenas dentro de suas instituições, utilizando intervenções fracas.

\section{$2.3 \mathrm{A3}$}

Reconhecida como berço da filosofia Lean Manufacturing e como referência em melhoria contínua, a Toyota desenvolveu ao longo dos anos uma abordagem de solução de problemas considerada chave para as melhorias na organização: o processo de gerenciamento $A 3$, relatório $A 3$, ou simplesmente $A 3$ (SOBEK II; 
SMALLEY, 2011). O relatório A3 para solução de problemas, adaptado da Toyota, é uma ferramenta potencialmente útil para a melhoria contínua nas organizações, ele simultaneamente documenta os resultados chave dos esforços de soluções de problemas de maneira concisa e incorpora uma completa metodologia de solução de problemas que começa com um profundo entendimento de como o trabalho realmente é feito (SOBEK; JIMMERSON, 2006). Na Toyota nunca houve o objetivo declarado de implantar o processo de gerenciamento A3. Em vez disso, o A3 emergiu como o método por meio do qual foram unidos dois importantes processos de gerenciamento do trabalho: hoshin kanri (gerenciamento da estratégia) e resolução de problemas (SHOOK, 2008).

O nome A3 se deve ao tamanho do papel (29,7 centímetros por 42 centímetros) utilizado para o relatório que, por ser o maior tamanho compatível com impressoras e copiadoras tradicionais, facilita o trabalho colaborativo, permitindo que a equipe compartilhe cópias do trabalho em andamento (KIMSEY, 2010). O relatório A3 é composto por uma sequência de campos arranjados em um template. Em cada um desses campos a equipe descreve, em sequência: o contexto e a importância do problema analisado; as condições atuais do problema; os resultados desejados; as relações causais da situação; as contramedidas propostas; o plano de ações para correção do problema; e o esboço do processo de acompanhamento (SHOOK, 2009). Sobek II e Smalley (2011) citam que as abordagens de solução de problemas em uso na Toyota são fortemente influenciadas pela metodologia PDCA (Plan, Do, Check, $A c t$ ), sendo o A3 a principal ferramenta para implementar a gestão PDCA nos diversos departamentos e níveis da organização. O PDCA pode ser visto como um método de tomada de decisões para a resolução de problemas organizacionais, que indica o caminho a ser seguido para que as metas estipuladas possam ser alcançadas (FONSECA, 2006). Shook (2008) enfatiza que não há modelo fixo e correto para um $A 3$, pois não é o formato do relatório que importa, mas o pensamento subjacente ao ciclo PDCA.

Para Sobek II e Smalley (2011) o poder do A3 não deriva do relatório em si, mas da cultura e modelo mental requeridos para a implementação do processo de gerenciamento $A 3$, um conjunto de dinâmicas ao qual denominam pensamento $A 3$. Kimsey (2010) destaca como um aspecto importante da metodologia Lean o pensamento $A 3$, o qual define como um processo de construção de consenso que Revista Produção Online. Florianópolis, SC, v. 20, n. 1, p. 63-94, 2020 
se utiliza de uma metodologia documentada e sistematizada, a qual permite à equipe envolvida em um projeto saber em que ponto estão e para onde estão seguindo. O A3 é uma manifestação visual de um processo conceitual de resolução de problemas que envolve diálogo contínuo entre o responsável por um problema e outras pessoas em uma organização (SHOOK, 2008).

O A3 funciona tanto como uma ferramenta de resolução de problemas quanto como um processo estruturado para criar solucionadores de problemas, pois auxilia na disseminação do método científico que força os indivíduos a observar a realidade para atingir suas metas (SHOOK, 2008). Segundo Shook (2009) o A3 serve como um mecanismo de ensino de análise de causa raiz e pensamento científico, enquanto alinha os interesses de departamentos individuais da organização ao encorajar o diálogo construtivo e ajudar as pessoas a aprenderem umas com as outras. Sobek e Jimmerson (2006) citam como benefícios do uso do relatório A3 a facilidade de movimentação da ferramenta, permitindo que o trabalho seja documentado no local onde acontece; a possibilidade da contribuição das pessoas nos locais de trabalho, sem necessidade de treinamentos elaborados; a natureza visual do relatório, que permite uma representação mais próxima dos sistemas reais; e finalmente o fato de um relatório ser uma forma sucinta de representar todas as etapas da solução de um problema.

Ao aplicar o processo de gerenciamento A3 em um ambiente hospitalar, Jimmerson et al. (2005) verificaram que o uso do A3 facilita uma comunicação sucinta, clara e objetiva entre os departamentos, neutralizando conflitos ao permitir que as equipes focassem no que é correto para os pacientes. Os autores citam, entre os benefícios do uso do método, que não são necessárias longas horas de capacitação, todavia acrescentando que a dificuldade mais comum observada é encontrar tempo para solucionar os problemas. Kimsey (2010) relata a utilização do A3 no setor da saúde para melhorias de eficiência e segurança, além de redução de custos, observando resultados como aumento no trabalho em equipe, criação de áreas e processos de interface mais amigável, mudanças no estilo de gestão, aumento do envolvimento dos funcionários e melhorias na cadeia de suprimentos da área operatória. O autor verificou que os membros envolvidos na aplicação do A3 se orgulharam do trabalho realizado, tendo sido beneficiados pelo aprendizado gerado no processo.

Revista Produção Online. Florianópolis, SC, v. 20, n. 1, p. 63-94, 2020 


\subsection{Análise de Causa Raiz}

Análise de Causa Raiz, ou Root Cause Analysis (RCA), é uma designação utilizada para o método de investigação de problemas baseado em análise de causas que pode ser conduzido através de diversas ferramentas. Não é objetivo de esse estudo analisar os diferentes métodos de condução, essa análise pode ser encontrada nos trabalhos de Livingston et al. (2001) e Doggett (2005). Rooney (2004) descreve RCA como um método "desenvolvido para auxiliar a identificar não apenas o que e como um evento ocorreu, mas também por que ele ocorreu", num processo utilizado para investigação e categorização das causas raízes de um evento. Para Okes (2005), RCA é o processo estruturado que parte dos sintomas de um problema para sua definição, estabelecendo as possíveis causas até encontrar a causa real, em um processo iterativo que combina pensamento divergente $\mathrm{e}$ convergente. Análise de causa raiz é um processo de análise para definir um problema, compreender o mecanismo responsável pela transição de um estado desejável para uma condição indesejável, o que implica encontrar a fonte específica que originou o problema para que ações efetivas possam ser tomadas de forma a evitar a recorrência da situação.

Não há consenso na literatura quanto à definição de causa raiz, Dew (1991) define causa raiz como a causa que se efetivamente corrigida ou eliminada impede a recorrência da situação. Para Ronney (2004), uma série de fatores, inclusive econômicos, devem ser considerados para a definição de causa raiz, citando os seguintes:

1. Causas raiz são causas profundamente específicas.

2. Causas raiz são aquelas que podem razoavelmente ser identificadas.

3. Causas raiz são aquelas que a administração tem controle para corrigir.

4. Causas raiz são aquelas para as quais recomendações efetivas para prevenir a recorrência podem ser geradas.

O autor defende que se não houver a viabilidade de atuar para a correção ou eliminação da causa, essa não deve ser apontada como causa raiz.

Bates (1998) acrescenta que muitas metodologias de solução de problemas implicam que a fase de diagnóstico está encerrada com a descoberta das causas raízes, todavia defende que o diagnóstico apenas aponta potenciais causas 
fundamentais, sendo a efetividade da solução que finalmente identifica as verdadeiras causas raízes. A busca pela causa raiz é um processo de questionamento, e, RCA implica em fazer perguntas difíceis e algumas vezes embaraçosas, sobre como a organização é gerida, por isso pode ser ignorada por razões políticas internas (DEW, 1991). Teixeira e Cassiani (2010) defendem que "a análise de causa raiz deve ser adotada pelas instituições, pois sua proposta não se resume em apenas encontrar as causas raízes, mas em clarear de fato o que ocorreu, a fim de prevenir e evitar que novos episódios aconteçam”.

ledema et al. (2006) traçam paralelos entre a RCA e a prática da medicina no século XXI, discorrendo que ambas buscam isolar a verdadeira causa de um evento, encaixando-a em termos técnico-racionais, e observando ainda que a aplicação da RCA estabelece uma autocrítica que espelha uma tendência de autoanálise observada na medicina contemporânea. Bagian et al. (2002) observaram através de RCAs realizadas no setor hospitalar que o processo pode resultar em ações de alto impacto amplamente aplicáveis, acrescentando que o aprendizado obtido na aplicação do RCA em eventos evitados é tão rico quanto da análise de eventos ocorridos. Os autores acrescentam que o uso do RCA pode resultar em ações de grande abrangência e alto impacto. Ao associar grupos multidisciplinares e de diferentes departamentos e unidades, a equipe hospitalar tem a possibilidade de estabelecer relações que são baseadas em princípios muito diferentes da especialização profissional e da progressão de carreira, permitindo que o aprendizado não se restrinja apenas aos envolvidos com o evento, mas a todos envolvidos na RCA (IEDEMA et al., 2006).

Apesar das experiências bem sucedidas relatadas na literatura, Wu et al. (2008) apresentam uma visão mais pragmática do uso da Análise de Causa Raiz como um método central para mitigar riscos e gerar aprendizado com erros; afirmando que mesmo que tenham sido obtidos alguns benefícios, incluindo aumento na percepção de processos falhos e a solução de problemas específicos, há uma tendência de percepção de que essa abordagem tem efetividade limitada. Ainda segundo os autores, muitas organizações do setor da saúde, principalmente as menores, podem estar despendendo uma porção significativa dos seus recursos de melhoria da qualidade em intervenções que possuem pequenas chances de reduzirem riscos ou danos. Já Novaretti (2014) é mais otimista ao afirmar que é 
reconhecido que a metodologia RCA apresenta limitações, mas que os benefícios que podem ser derivados dela, devido ao raciocínio crítico sobre cada incidente ocorrido, a implantação das ações corretivas que evitam a ocorrência desses incidentes e seu caráter preventivo, superam as suas fragilidades.

\section{MÉTODO DE PESQUISA}

\subsection{Estratégia de pesquisa}

A estratégia de pesquisa utilizada nesse trabalho é de estudo de caso, o qual consiste na utilização de dois métodos aplicados para solução de problemas em uma emergência hospitalar. Para adequação a essa estratégia foi selecionado um caso relevante, considerando múltiplas fontes de evidência. $O$ estudo foi realizado em um hospital universitário de grande porte localizado na região sul do Brasil. Integrante da rede de hospitais universitários do Ministério da Educação (MEC) e vinculado academicamente a uma universidade federal, o hospital em questão tem a missão de oferecer serviços assistenciais à comunidade, além de ser área de ensino para a universidade e promover a realização de pesquisas científicas e tecnológicas. O hospital foi selecionado devido a três características: (i) a possibilidade de acesso e disponibilidade dos funcionários para colaboração na execução da pesquisa; (ii) a existência de iniciativas de melhoria prévias, alinhadas ao objetivo desse estudo e (iii) o interesse das lideranças da organização no uso de diferentes métodos de solução de problemas.

O trabalho iniciou com a delimitação do estudo, etapa na qual foram definidos os métodos de solução de problemas utilizados, o processo abordado e os problemas enfatizados. A segunda etapa consistiu na seleção da unidade do hospital para realização do estudo. Após a escolha da unidade, iniciou-se a aplicação dos métodos selecionados, os quais podem ser divididos nas etapas correspondentes ao ciclo PDCA: (a) planejamento; (b) execução e (c) verificação e ação. As etapas de verificação e ação foram agrupadas por corresponderem ao preenchimento do mesmo campo no relatório $A 3$, não havendo etapa correspondente prevista no método RCA. O trabalho foi concluído após a avaliação 
dos critérios selecionados para a comparação dos métodos. A relação das etapas do estudo com as etapas das aplicações dos métodos é apresentada na figura 1.

Figura 1 - Etapas dos métodos e etapas correspondentes do estudo

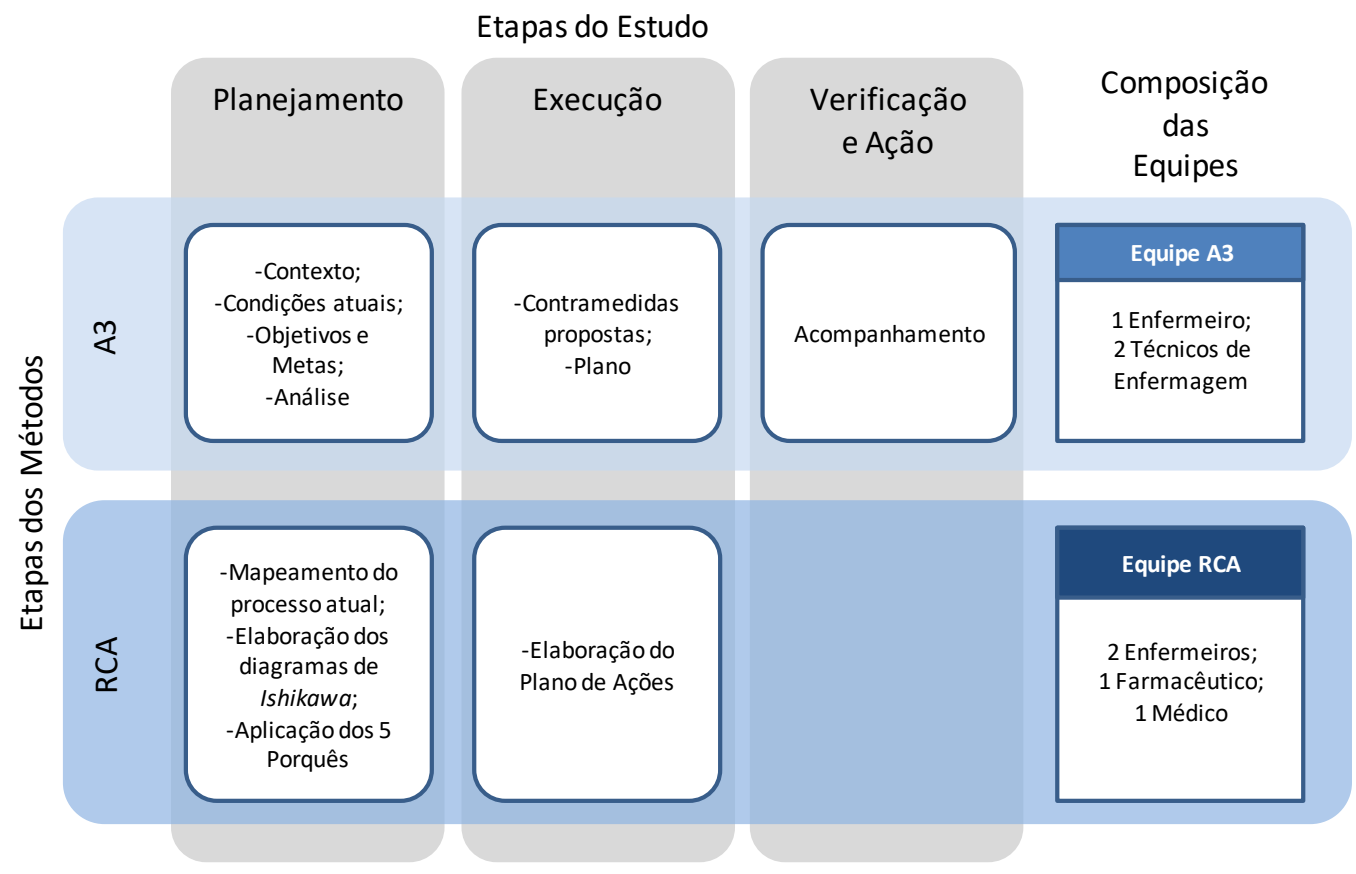

Em relação ao processo abordado, ele foi selecionado a partir de estudo descrito em Pasin (2015), no qual a segurança do processo de medicação na mesma unidade foi avaliada pela perspectiva do pensamento Lean. O referido estudo identificou os problemas que afetam os requisitos dos clientes de uma unidade hospitalar para, com base nisso, estabelecer prioridades e planejar melhorias. De acordo com os problemas priorizados no trabalho citado, as demandas atuais da instituição e a recomendação das lideranças envolvidas, foi selecionado para o presente estudo o processo de prescrição e medicação, com ênfase nos problemas relacionados ao atraso da prescrição médica e a erros de medicação.

A unidade foi selecionada de acordo com a frequência de registros de pacientes sem prescrição vigente, priorizando-se as unidades com maior número de ocorrências no período de 12 meses. Além disso, três lideranças do hospital e dois especialistas do departamento de enfermagem também opinaram na seleção. Para aplicação dos métodos foi selecionada a unidade de emergência do hospital, a qual é dividida em áreas funcionais que se diferenciam pela classificação de risco dos 
pacientes acolhidos, contando com integrantes de diferentes equipes em um mesmo turno. Previamente ao início do estudo, foram realizadas reuniões com as lideranças das equipes médica, de enfermagem e da farmácia da emergência, nas quais foram explicados os métodos abordados, os problemas relatados e a adequação do setor aos objetivos dessa pesquisa. Também foi realizada uma visita informal às instalações do setor. A necessidade da participação de representantes das áreas com experiência no processo e disponibilidade para o estudo foi apresentada durante essas reuniões, nas quais as lideranças definiram os membros das equipes de trabalho de acordo com a experiência e disponibilidade, bem como pela vontade de participar da iniciativa.

Também foi definida nessas reuniões a data inicial dos encontros destinados à aplicação dos métodos. Participaram desse trabalho representantes de todas as áreas envolvidas no processo de prescrição e medicação, membros da enfermagem, farmácia e do corpo clínico médico. Por questões éticas e de adequação ao objetivo do trabalho, delimitou-se a abrangência do estudo aos setores destinados ao atendimento adulto.

As duas abordagens de solução de problemas, RCA e A3, foram aplicadas no processo de prescrição e medicação da unidade de emergência do hospital. Cada método foi aplicado com diferentes participantes, de forma a evitar contato entre as equipes envolvidas, isolando assim as falhas identificadas e melhorias sugeridas por cada grupo para posterior avaliação. Ambos os métodos partiram do mapa de processo, o qual foi desenhado em campo com as equipes no início da aplicação de cada método, conforme as informações prestadas pelos representantes das áreas envolvidas no processo de prescrição e medicação, de forma a retratar fielmente a execução do processo na forma como é realizado rotineiramente. A etapa final da aplicação dos métodos consistiu na identificação das ações de melhoria sugeridas pelos envolvidos, seguindo da elaboração dos planos de ações com as melhorias elencadas. Ações de acompanhamento para essas melhorias foram definidas, entretanto esse acompanhamento estava fora do escopo desse trabalho.

As ações de melhoria resultantes foram avaliadas por três assessores de operações assistenciais da administração central do hospital, com auxílio de um assessor da farmácia, por possuírem conhecimento do processo e uma visão global das unidades. Esses avaliadores não participaram da aplicação de nenhum dos 
métodos, a exceção de um dos assessores de operações assistenciais que acompanhou, como observador, uma das reuniões de aplicação do RCA, permitindo que classificassem de forma isenta as ações de acordo com dois critérios: a) dificuldade de implementação da ação e b) a possibilidade de replicação da ação entre as unidades do hospital. A forma de avaliação desses critérios é apresentada no quadro 1. Após a avaliação das ações, os valores correspondentes às classificações nesses dois critérios foram multiplicados para gerar um indicador único denominado Prioridade, do tipo maior melhor, que permite a priorização das ações para implementação. Esse indicador foi utilizado como critério adicional para avaliação dos métodos, em conjunto com os critérios citados anteriormente, de forma a quantificar a atratividade dos planos de ações resultantes para instituição. Os métodos também foram avaliados quanto ao tempo necessário para aplicação, o número de envolvidos, a necessidade de capacitação e o número total de oportunidade de melhoria identificadas.

Quadro 1 - Régua utilizada para avaliação dos critérios, com os valores definidos
e suas respectivas interpretações
\begin{tabular}{|ll|}
\hline Critério: Dificuldade de implementação \\
\hline Valor & Interpretação \\
\hline 1 & Ação de implementação muito difícil \\
3 & Ação com dificuldade média de implementação \\
9 & Ação de implementação fácil \\
\hline Critério: Possibilidade de replicação entre as unidades \\
\hline Valor & Interpretação \\
\hline 1 & Ação válida apenas para unidade onde foi proposta \\
3 & Ação válida para algumas unidades \\
9 & Ação válida para todo o hospital \\
\hline
\end{tabular}

\subsection{Coleta de dados}

Os dados relacionados com a aplicação dos métodos foram coletados por meio de múltiplas fontes de evidências, apresentadas no quadro 2. 
Quadro 2 - Fontes de dados associadas às diferentes etapas do estudo

\begin{tabular}{|c|c|c|c|c|}
\hline & \multicolumn{4}{|c|}{ Fonte de dados } \\
\hline Etapa do estudo & $\begin{array}{c}\text { Observação } \\
\text { não participante }\end{array}$ & $\begin{array}{l}\text { Procedimentos } \\
\text { operacionais } \\
\text { padronizados }\end{array}$ & $\begin{array}{l}\text { Observação } \\
\text { participante }\end{array}$ & $\begin{array}{l}\text { Entrevista } \\
\text { semi- } \\
\text { estruturada }\end{array}$ \\
\hline Delimitação do estudo & $x$ & $x$ & $x$ & \\
\hline Seleção da unidade & $x$ & & $x$ & \\
\hline Análise do processo & $\mathrm{X}$ & $\mathrm{x}$ & & \\
\hline Identificação de problemas & & & $x$ & \\
\hline Análise das causas & & & $\mathrm{X}$ & \\
\hline Identificação de melhorias & & & $\mathrm{X}$ & \\
\hline Avaliação dos critérios & & & $\mathrm{X}$ & $\mathrm{X}$ \\
\hline Total & $4 \mathrm{~h}$ & & $16 \mathrm{~h}$ & $1 \mathrm{~h}$ \\
\hline
\end{tabular}

Duas observações não participantes foram realizadas em visitas às instalações da emergência para avaliar a adequação da unidade aos objetivos do estudo e para permitir um melhor entendimento do processo abordado, as informações coletadas durante essas observações foram registradas em um diário de campo. Procedimentos operacionais padronizados utilizados nas investigações de não conformidades da instituição foram consultados para orientar a delimitação do estudo, bem como procedimentos específicos da unidade de emergência embasaram a análise do processo. Um dos autores do presente estudo atuou de forma ativa nas etapas de delimitação do estudo e na seleção da unidade, bem como orientando as equipes quanto à utilização dos métodos durante as reuniões de trabalho, todavia sem interferir nas informações prestadas nessas etapas. As reuniões de trabalho foram registradas em atas.

Os profissionais envolvidos no estudo foram convidados, após a conclusão dos planos de ações, a responder uma entrevista sobre o método abordado com a equipe de trabalho da qual fizeram parte. As entrevistas foram individuais e gravadas, visando registrar a manifestação da percepção dos envolvidos quanto à possibilidade de aplicação da metodologia, qualificação necessária, dificuldades na utilização e pontos fortes observados. As entrevistas foram autorizadas mediante assinatura de um termo de consentimento. Ao todo foram entrevistados seis participantes, sendo quatro membros da equipe do RCA e dois da equipe da aplicação do A3.

Os planos de ações elaborados foram apresentados às lideranças competentes para a definição dos responsáveis, seguindo-se da implementação e 
acompanhamento das melhorias consideradas viáveis, não sendo objetivo desse estudo o acompanhamento da execução das melhorias. Todos os dados coletados no estudo, bem como orientações quanto às ferramentas e procedimentos utilizados foram compartilhados tanto com as equipes envolvidas quanto com a Assessoria de Operações Assistenciais da Administração Central do hospital para a disseminação dos novos procedimentos.

\subsection{Análise de dados}

A análise dos dados foi realizada por análise do conteúdo das entrevistas, dos registros de observações e pela compilação dos resultados da avaliação das melhorias propostas conforme os critérios adotados. Durante as aplicações dos métodos, informações específicas foram necessárias para a conclusão de cada etapa e o início da seguinte. Os dados analisados para a obtenção dessas informações em cada etapa são apresentados no quadro 3.

Quadro 3 - Informações buscadas nas diferentes etapas do estudo

\begin{tabular}{|l|l|l|}
\hline \multicolumn{1}{|c|}{ Dado analisado } & \multicolumn{1}{|c|}{ Informação buscada nas fontes de dados } & $\begin{array}{c}\text { Etapa do estudo } \\
\text { relacionada }\end{array}$ \\
\hline Problemas & $\begin{array}{l}\text { Incidentes já observados anteriormente; } \\
\text { diferenças entre o processo realizado e os } \\
\text { procedimentos; indicadores abaixo de metas } \\
\text { estipuladas. }\end{array}$ & $\begin{array}{l}\text { Delimitação do } \\
\text { estudo } \\
\text { Análise do processo } \\
\text { Identificação de } \\
\text { problemas }\end{array}$ \\
\hline Causas & $\begin{array}{l}\text { Motivo da ocorrência do problema observado; } \\
\text { possibilidade de gestão da organização sob o } \\
\text { motivo encontrado. }\end{array}$ & Análise de causas \\
\hline Melhorias & $\begin{array}{l}\text { Ações corretivas e/ou preventivas que eliminem } \\
\text { as causas identificadas, de acordo com a } \\
\text { experiência dos envolvidos. }\end{array}$ & $\begin{array}{l}\text { Identificação de } \\
\text { melhorias }\end{array}$ \\
\hline Critérios comparativos & $\begin{array}{l}\text { Experiência necessária para aplicação dos } \\
\text { métodos; dificuldades relatadas pelos } \\
\text { participantes; pontos positivos observados; } \\
\text { dificuldade de implementação e possibilidade de } \\
\text { replicação das ações de melhoria. }\end{array}$ & $\begin{array}{l}\text { Avaliação dos } \\
\text { critérios }\end{array}$ \\
\hline
\end{tabular}

O mapa do processo de prescrição e medicação foi representado com auxílio do software Gliffy Diagrams ${ }^{\circledR}$. Para a elaboração dos planos de ações, bem como a posterior classificação desses pelos critérios de avaliação das ações utilizou-se o software Microsoft Excel ${ }^{\circledR} 2013$. 


\subsection{Apresentação do processo}

O serviço de emergência dispõe de uma área de cerca de 1,4 mil metros quadrados, dividida entre 49 leitos para pacientes adultos e 9 leitos pediátricos, nos quais são atendidas pessoas em situação de urgência nas especialidades de clinica médica, cirurgia, ginecologia, pediatria e obstetrícia. $O$ atendimento segue a classificação de risco de Manchester, sistema internacional que prioriza o atendimento dos pacientes em situação mais grave. A unidade de internação de adultos é dividida em quatro salas equipadas de acordo com a classificação de risco dos pacientes, sendo uma delas destinada a tratamento intensivo e semi-intensivo, uma para pacientes com baixo risco, uma para pacientes com médio e alto risco e uma unidade intermediária. A unidade conta também com consultórios e uma área de triagem. Destinada a usuários do Sistema Único de Saúde (SUS), a demanda por atendimento na emergência é constantemente superior à capacidade de projeto, ocasionando frequente superlotação da unidade.

O processo de prescrição na emergência do hospital estudado é realizado de forma mista entre atividades manuais e eletrônicas. A prescrição eletrônica utiliza um sistema desenvolvido internamente na organização, o qual é frequentemente atualizado para contemplar todos os procedimentos do hospital. Apesar de implementada como forma de facilitar a comunicação e reduzir falhas humanas, a prescrição eletrônica revela uma série de desafios próprios. Segundo estudo conduzido por Koppel et al. (2005), a prescrição eletrônica pode levar ao aumento de erros de prescrição em 22 situações identificadas, sendo recomendação dos autores que as instituições foquem na organização do trabalho, não na tecnologia utilizada.

A necessidade de atividades manuais envolvidas no processo de prescrição se dá pela dificuldade de acesso a computadores disponíveis durante a rotina de trabalho das equipes de atendimento, as quais utilizam prescrições impressas para orientação. Dessa forma é necessário imprimir as prescrições geradas no sistema e disponibiliza-las aos profissionais pertinentes, que farão uso delas como guia para dar seguimento ao processo de medicação. A prescrição é vigente por um período de 24 horas. Após esse período uma nova prescrição deve ser registrada, caso contrário o paciente é considerado sem prescrição. São realizados três tipos de 
prescrição no hospital avaliado: a) prescrição de admissão, que consiste na primeira prescrição que o paciente recebe no ato da internação; b) prescrição próxima, que consiste na nova prescrição após o vencimento da prescrição vigente de um paciente já internado e c) prescrição de urgência, que visa atender necessidades imediatas relacionadas ao quadro de saúde do paciente, podendo ser realizada em um primeiro momento de forma verbal para agilizar o processo, com registro posterior à administração do medicamento. A necessidade de uma prescrição próxima na emergência se dá devido à característica do hospital avaliado de possuir pacientes com permanência superior a 24 horas na unidade de emergência, assemelhando a unidade, nesse sentido, às demais unidades de internação do hospital.

Após a prescrição pelo médico, o processo de medicação passa a ser um esforço conjunto das equipes da farmácia e enfermagem, sendo os medicamentos disponibilizados pela primeira equipe, de acordo com a prescrição eletrônica, e preparados e aplicados pela segunda, de acordo com a prescrição impressa. Cabe aos técnicos de enfermagem o preparo dos medicamentos, que abrange separar os medicamentos de cada paciente, diluir as doses de acordo com a prescrição e preparar os acessos dos pacientes para a medicação. Após o preparo dos medicamentos o técnico de enfermagem deve se deslocar até o leito do paciente, onde administrará o medicamento prescrito.

Um grande desafio relatado no hospital é o registro de não conformidades ocorridas durante o processo, visto que erros rotineiros ocorridos durante 0 desenvolvimento das atividades tendem a ser contornados, impedindo suas detecções para registro. A carência nos registros dificulta a mensuração dos problemas relatados, considerando que só serão registrados quando resultarem em dano grave, o que ocorre com menor frequência. Por esse motivo optou-se por aplicar os métodos a partir de uma análise do processo ao invés de um evento específico do passado, visando atuar preventivamente em falhas que normalmente não são registradas.

\subsection{Aplicação A3}

A metodologia A3 foi selecionada pelo crescente interesse das lideranças do Revista Produção Online. Florianópolis, SC, v. 20, n. 1, p. 63-94, 2020 
hospital nas práticas associadas à filosofia Lean. Iniciativas pontuais de execução de relatórios A3 já haviam sido realizadas na instituição, porém sem disseminação posterior da prática. O relatório A3 utilizado para o estudo é apresentado na figura 2, adaptado com base no modelo de relatório sugerido por Shook (2008). Esse modelo contempla os campos: I) Contexto; II) Condições atuais; III) Objetivos e metas; IV) Análise; V) Contramedidas propostas; VI) Plano de melhorias e VII) Acompanhamento. Os campos incluídos no relatório $A 3$, bem como a ordem e disposição na qual são apresentados, visam induzir o pensamento PDCA, possibilitando que a equipe visualize tanto onde se encontra quanto, idealmente, para onde está seguindo (KIMSEY, 2010).

Figura 2 - Modelo A3 utilizado para aplicação do método
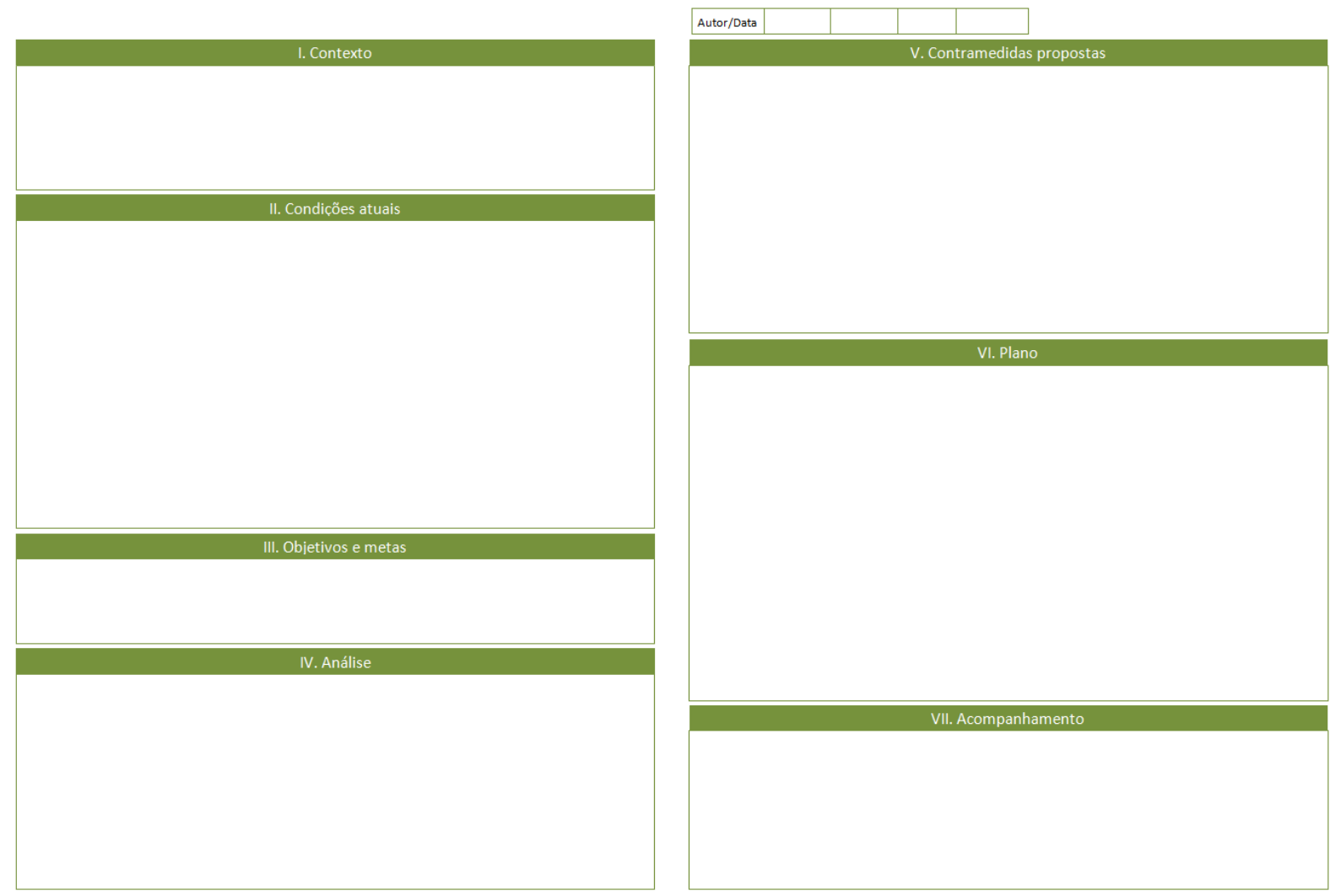

Para aplicação do processo de gerenciamento A3, o relatório foi impresso em uma folha de tamanho $\mathrm{A} 3$ e preenchido manualmente conforme o desenvolvimento do método, mantendo todos os envolvidos em seu ambiente rotineiro de trabalho. Os envolvidos foram orientados quanto ao objetivo do relatório, que deveria focar nos problemas de atraso na prescrição e erros de medicação, sem se limitar a esses. Também foram orientados quanto à metodologia relacionada ao preenchimento do

Revista Produção Online. Florianópolis, SC, v. 20, n. 1, p. 63-94, 2020 
relatório e ao conteúdo esperado para cada campo, mantendo a liberdade para que escolhessem a melhor forma de registrar esse conteúdo. Shook (2008) ressalta que o ponto principal do A3 não é o papel ou o formato; é o processo de construção na sua totalidade. A equipe envolvida diretamente consistiu em um enfermeiro e dois técnicos de enfermagem, indicados pela liderança da área devido a sua experiência no setor e motivação para sugerir melhorias. O preenchimento completo do relatório se deu ao longo de quatro encontros com duração de uma hora, realizados durante o expediente dos envolvidos.

A primeira etapa da aplicação constitui o planejamento, essa etapa inclui o preenchimento do campo contexto, o campo condições atuais, a definição dos objetivos e metas e o preenchimento do campo análise. Nessa etapa a equipe foi orientada quanto ao objetivo do relatório: identificar e prevenir eventuais falhas no processo de prescrição e medicação que possam resultar nos problemas de atraso na prescrição e erros de medicação. Para a definição das condições atuais, partiu-se do mapa do processo previamente desenhado com os representantes da farmácia e do corpo médico, o qual foi complementado pelos membros da equipe de enfermagem com suas atividades durante a execução do relatório. Após a definição e mapeamento das atividades executadas, a equipe foi convidada a relatar falhas possíveis e observadas em cada uma das etapas do processo, registrando-as no campo condições atuais do relatório, correspondendo à etapa do estudo de identificação de problemas. Para abordar as atividades realizadas por outras áreas que não a enfermagem, a equipe contava com a consulta de profissionais dessas áreas correlatas, que esclareciam dúvidas ou forneciam informações conforme necessário. Com a definição das condições atuais, a equipe estipulou metas para a realização do trabalho, as quais partiram dos problemas observados de forma qualitativa e de indicadores da área de forma quantitativa. Para o preenchimento do campo análise, as falhas listadas na situação atual foram analisadas de forma a encontrar suas respectivas causas potenciais, registrado em um modelo de árvore de causas no relatório. Na sequência, na etapa de execução, foram propostas contramedidas para as causas potenciais identificadas, as quais foram transpostas para ações, registradas no plano de ação resultante do trabalho. Um plano de acompanhamento das melhorias propostas foi elaborado pela equipe, a ser 
executado após a implementação do plano de ações, correspondendo às etapas de verificação e ação.

\subsection{Aplicação RCA}

Atualmente utilizado para investigação de incidentes no hospital estudado, o método RCA é de uso mandatório para investigação de acidentes clínicos classificados como dano grave, de acordo com a matriz de classificação de dano adotada pela instituição. Recomendado para investigação de acidentes clínicos pela United States Veterans Affairs National Patient Safety Foundation (NPSF), organização sediada nos Estados Unidos que credencia instituições hospitalares, o método RCA é conduzido no hospital pela Gerência de Risco Sanitário Hospitalar, utilizando uma adaptação da metodologia baseada em recomendações da NPSF e da National Health Service (NHS), órgão britânico de serviços assistenciais a saúde. Por solicitação da liderança da Gerência de Risco Sanitário Hospitalar, o estudo utilizou as mesmas etapas e ferramentas previstas nas RCAs conduzidas no hospital. Entre as recomendações da instituição está a composição da equipe, que é recomendado consistir de quatro ou cinco pessoas, devendo ter natureza interdisciplinar com conhecimento a respeito do processo envolvido no evento; membros de diferentes áreas de atuação, visando incentivar o pensamento criativo e presença de lideranças dos departamentos, de forma a auxiliar na credibilidade do trabalho. A equipe da aplicação do método RCA foi formada por um representante da farmácia, a chefe do serviço de enfermagem da emergência, um enfermeiro e um médico. A equipe se reuniu em um total de quatro reuniões semanais, com duração de uma hora cada.

Por não partir de um evento específico, o método RCA iniciou com o mapeamento do processo atual, no qual todas as atividades cotidianamente realizadas pelas áreas envolvidas foram listadas e organizadas de acordo com a sequência de execução. Essa etapa corresponde à etapa do estudo de planejamento. Devido à existência de diferentes tipos de prescrição, a equipe optou por limitar a análise ao processo de prescrição próxima, por entender que é nesse processo que se origina o atraso de prescrição, além de representar a maioria das prescrições realizadas. 
Com o mapa de processo como base, a equipe foi incentivada a relatar todas as possíveis falhas em cada atividade, descrevendo se o impacto da falha no processo teria maior potencial no atraso da prescrição ou em erros de medicação, na etapa de identificação de problemas. De acordo com os relatos da equipe, as falhas foram organizadas em Diagramas de Ishikawa separados pelos problemas de Atraso da prescrição e Erros de medicação.

As falhas que, na avaliação da equipe, não correspondiam diretamente às causas potenciais do problema abordado no diagrama de Ishikawa correspondente, foram submetidas à ferramenta 5 Porquês, de forma a identificar a causa raiz da falha, finalizando a etapa de planejamento. O uso do 5 Porquês no RCA é recomendado por Neily et al. (2003) e Okes (2005), todavia criticado por Card (2016), que condena o uso da ferramenta por simplificar excessivamente o processo exploratório, conduzindo a uma única linha analítica, dentre diversas possíveis, sendo, segundo o autor, mais recomendado como ferramenta de aprendizado do que para aplicações reais. O critério de parada utilizado na análise 5 Porquês foi a possibilidade de atuação da instituição sobre a causa identificada. Finalmente, na etapa de execução, para cada causa identificada a equipe foi incentivada a sugerir uma ação corretiva, as quais foram registradas no plano de ações, encerrando a aplicação da metodologia.

\section{RESULTADOS E DISCUSSÃO}

\subsection{Resultados A3}

O relatório A3 completo, preenchido pela equipe, é apresentado na figura 3 . A aplicação do método A3 resultou em 13 ações de melhoria propostas, as quais foram classificadas com uma média de 2,1 para o critério dificuldade de implementação da ação e 3,5 para possibilidade de replicação da ação entre as unidades do hospital. A média do indicador Prioridade, diante de um máximo possível de 81 , foi 5,8. As ações resultantes, bem como suas avaliações, são apresentadas no quadro 4. 
Figura 3 - Relatório A3 após o completo preenchimento pela equipe

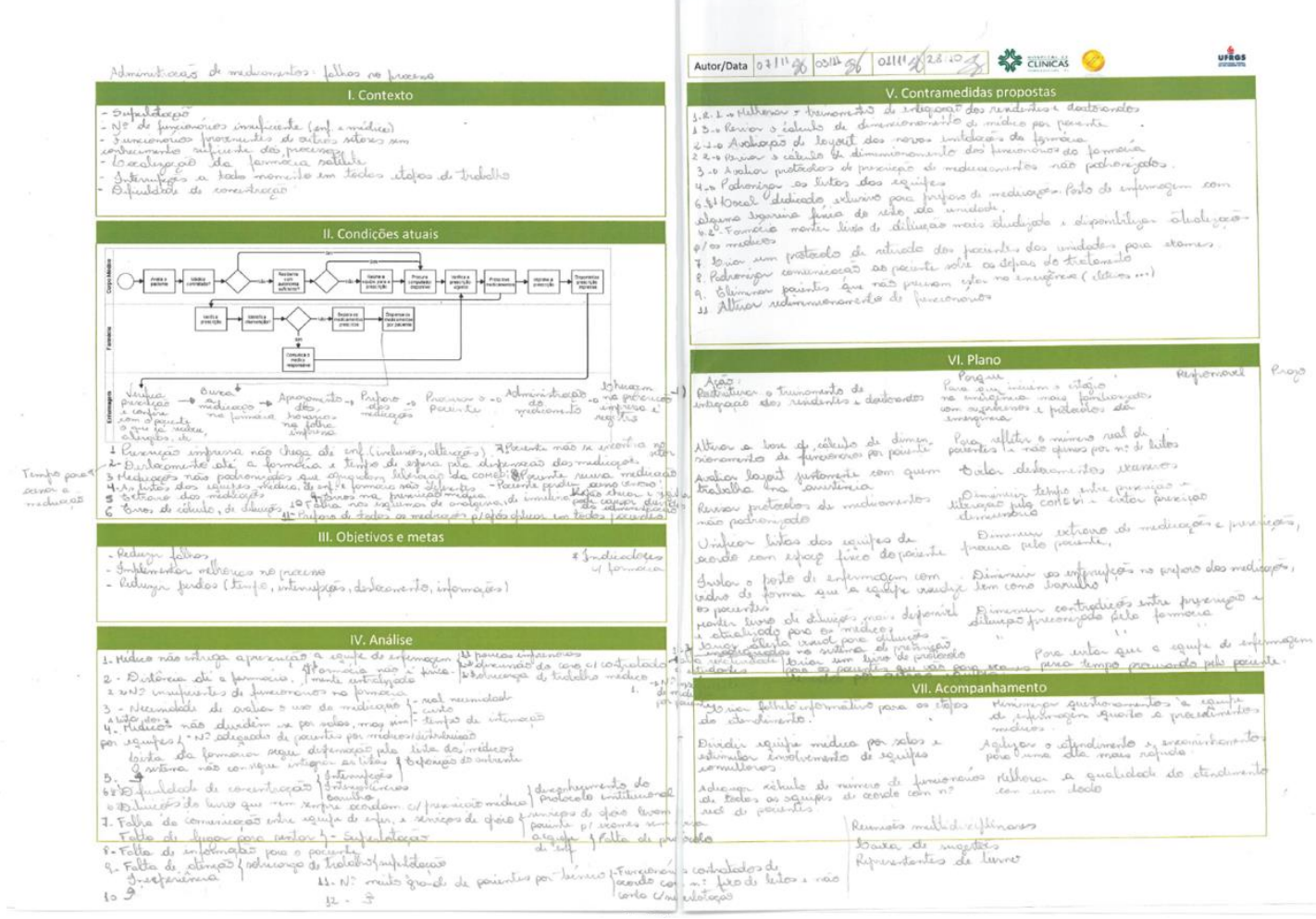

Quadro 4 - Ações de melhoria resultantes da aplicação da metodologia A3, classificadas de acordo com os critérios de dificuldade de aplicação e replicabilidade

\begin{tabular}{|c|l|c|c|c|}
\hline $\mathbf{N}^{\circ}$ & \multicolumn{1}{|c|}{ Ação Preventiva } & Dificuldade & Replicação & Prioridade \\
\hline 1 & $\begin{array}{l}\text { Reestruturar o treinamento de integração dos residentes } \\
\text { e doutorandos. }\end{array}$ & 1 & 9 & 9 \\
\hline 2 & $\begin{array}{l}\text { Alterar a base de cálculo de dimensionamento de } \\
\text { funcionários (médicos) por paciente. }\end{array}$ & 1 & 1 & 9 \\
\hline 3 & $\begin{array}{l}\text { Avaliar o layout das novas instalações da farmácia } \\
\text { juntamente com quem trabalha na assistência. }\end{array}$ & 1 & 1 & 1 \\
\hline 4 & $\begin{array}{l}\text { Alterar a base de cálculo de dimensionamento de } \\
\text { funcionários (da farmácia) por paciente. }\end{array}$ & 1 & 9 & 9 \\
\hline 5 & $\begin{array}{l}\text { Revisar protocolos de prescrição de medicamentos não } \\
\text { padronizados }\end{array}$ & 1 & 1 & 1 \\
\hline 6 & $\begin{array}{l}\text { Unificar listas das equipes de acordo com a localização } \\
\text { física do paciente. }\end{array}$ & 3 & 1 & 1 \\
\hline 7 & $\begin{array}{l}\text { Criar um livro de protocolo para os pacientes que vão } \\
\text { para os exames levados por outras equipes. }\end{array}$ & 3 & 27 \\
\hline 8 & Criar folheto informativo com as etapas do atendimento. \\
\hline 9 & $\begin{array}{l}\text { Isolar o posto de enfermagem com vidro de forma que a } \\
\text { equipe visualize os pacientes (sem ser interrompida). }\end{array}$ & 3 & 3 \\
\hline 10 & $\begin{array}{l}\text { Manter livro de diluições mais disponível e atualizado } \\
\text { para os médicos. }\end{array}$ & 3 & 9 & 9 \\
\hline 11 & $\begin{array}{l}\text { Criar alerta visual para diluições inadequadas no sistema } \\
\text { de prescrição. }\end{array}$ & 1 & 1 & 1 \\
\hline 12 & $\begin{array}{l}\text { Adequar cálculo de número de funcionários da } \\
\text { enfermagem de acordo com o número real de pacientes. }\end{array}$ & 1 & 1 & 1 \\
\hline 13 & $\begin{array}{l}\text { Dividir equipe médica por salas e estimular envolvimento } \\
\text { de equipes consultoras. }\end{array}$ & 1 & 1 & \\
\hline
\end{tabular}


No quadro 5 são relacionadas as possíveis falhas identificadas no processo de prescrição e medicação, as causas potenciais dessas falhas e quais ações preventivas foram propostas para as corrigir.

Quadro 5 - Falhas identificadas no processo associadas às potenciais causas e respectivas ações preventivas propostas

\begin{tabular}{|c|c|c|}
\hline Falha & Causa Potencial & Ação Preventiva \\
\hline $\begin{array}{l}\text { Prescrição impressa não } \\
\text { chega ao enfermeiro }\end{array}$ & Alta rotatividade de estudantes & 1 \\
\hline $\begin{array}{l}\text { Alterações na prescrição não } \\
\text { são comunicadas }\end{array}$ & Sobrecarga de trabalho do médico & 2 \\
\hline Atraso na medicação & Deslocamento excessivo até a farmácia & 3 \\
\hline Atraso na medicação & $\begin{array}{l}\text { Número insuficiente de funcionários na } \\
\text { farmácia }\end{array}$ & 4 \\
\hline Atraso na medicação & $\begin{array}{l}\text { Medicações não padronizadas que } \\
\text { aguardam liberação da COMEDI }\end{array}$ & 5 \\
\hline $\begin{array}{l}\text { Falhas de localização do } \\
\text { paciente }\end{array}$ & $\begin{array}{l}\text { Listas diferentes entre equipe médica e } \\
\text { enfermagem }\end{array}$ & 6 \\
\hline $\begin{array}{l}\text { Falhas de localização do } \\
\text { paciente }\end{array}$ & $\begin{array}{l}\text { Falha de comunicação entre serviços de } \\
\text { apoio e enfermagem }\end{array}$ & 7 \\
\hline Paciente recusa medicação & Falta de informação para o paciente & 8 \\
\hline $\begin{array}{l}\text { Erros de preparo de } \\
\text { medicamentos }\end{array}$ & Dificuldade de concentração & 9 \\
\hline $\begin{array}{l}\text { Erros de preparo de } \\
\text { medicamentos }\end{array}$ & $\begin{array}{l}\text { Diluições no livro nem sempre acordam } \\
\text { com a prescrição médica }\end{array}$ & 10 \\
\hline $\begin{array}{l}\text { Erros de preparo de } \\
\text { medicamentos }\end{array}$ & $\begin{array}{l}\text { Diluições no livro nem sempre acordam } \\
\text { com a prescrição médica }\end{array}$ & 11 \\
\hline $\begin{array}{l}\text { Erros de preparo de } \\
\text { medicamentos }\end{array}$ & $\begin{array}{l}\text { Número muito grande de pacientes por } \\
\text { técnico }\end{array}$ & 12 \\
\hline Erros na prescrição médica & $\begin{array}{l}\text { Falta de atenção/ Sobrecarga/ } \\
\text { Inexperiência }\end{array}$ & 13 \\
\hline
\end{tabular}

Três das ações propostas como resultado da aplicação do método A3 numeradas 2, 4 e 12 - foram consideradas incoerentes pelos responsáveis pela avaliação dos planos. Essas ações partem da premissa que o número de funcionários da emergência seria calculado de acordo com o número fixo de leitos previsto no projeto, premissa incorreta, segundo os avaliadores, que consideraram o número de funcionários adequado para a capacidade atual da unidade. De forma a refletir a incoerência relatada, essas três ações receberam os valores correspondentes à máxima dificuldade e mínima possibilidade de replicação, impactando nas médias da avaliação da metodologia A3.

Dois dos três profissionais envolvidos na aplicação do A3 responderam a entrevista sobre o método, sendo que nenhum deles alegou conhecimento prévio do método. Ambos afirmaram que a metodologia não é complexa em relação à aplicação ou ao aprendizado, porém um dos participantes citou que o ambiente da 
emergência acaba tornando a prática complexa, devido à suas características dinâmicas. Foram relatadas como dificuldades para aplicação do A3: (i) encontrar tempo e um local adequado, durante o período de trabalho, para se dedicar ao preenchimento do relatório; (ii) semelhança dos campos contramedidas e plano, que para um dos participantes à primeira vista pareciam ter o mesmo objetivo. $\mathrm{O}$ campo contramedidas visa registrar a forma proposta para eliminar as causas identificadas na análise, enquanto no campo plano, ações são detalhadas para possibilitar a implantação dessas contramedidas no processo. Idealmente no campo plano, responsáveis são definidos para a execução das ações propostas, todavia no presente estudo a definição de responsáveis foi delegada às lideranças da instituição, não sendo realizada durante o preenchimento do relatório. Foi unânime entre os entrevistados a percepção de que o tempo dedicado para execução do trabalho, que totalizou quatro horas de reuniões, foi adequado. Foram destacados dentre os pontos positivos na utilização do método $\mathrm{A} 3$ a troca de percepções com os colegas a respeito de pontos específicos do processo e a possibilidade de visualizar todas as informações necessárias em apenas uma folha. Enquanto um dos entrevistados afirmou que não seria possível obter os mesmos resultados do trabalho sem a utilização do $A 3$, outro respondeu acreditar que sim, ressaltando, porém que não teria sido tão fácil e teria levado mais tempo. Ambos concordaram que seria possível aplicar a mesma metodologia em outras áreas e processos do hospital. Os relatos se assemelham aos obtidos no estudo de Jimmerson et al. (2005), no qual os participantes da aplicação do A3 em um hospital reportaram que o uso do método acelerou assuntos já em desenvolvimento, facilitando também a comunicação entre departamentos. Um aspecto importante do presente estudo é o fato do A3 ter sido utilizado de forma limitada ao enfocar apenas em suas características de solução de problemas. Segundo Shook (2008), mais do um meio para solução de problemas, o A3 é um processo de gestão que possibilita e estimula o aprendizado por meio do método científico.

\subsection{Resultados RCA}

O mapa do processo desenhado pela equipe e utilizado como base para a aplicação do RCA é apresentado na figura 4. 
Figura 4 - Mapa do processo de prescrição próxima e medicação na emergência

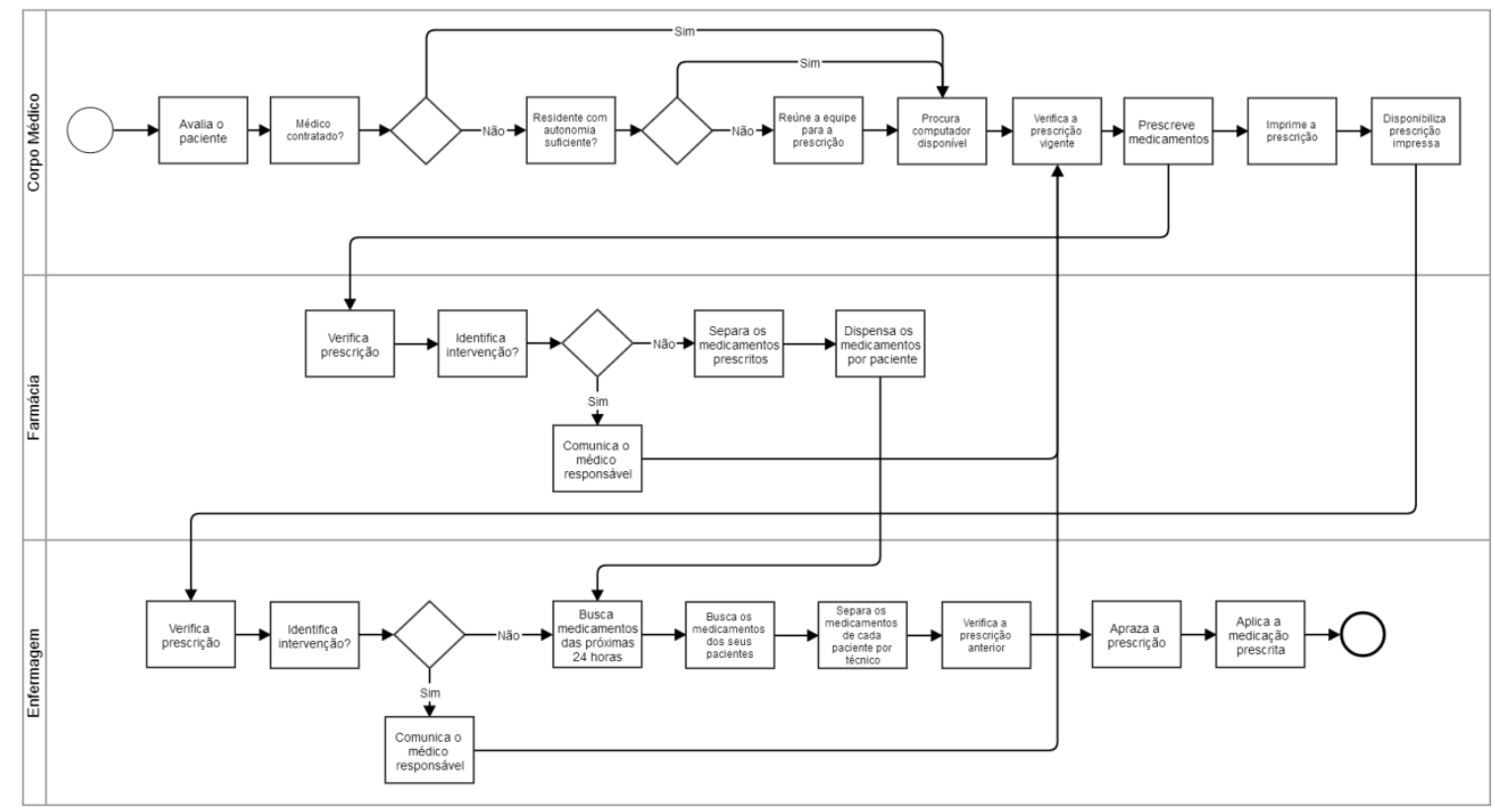

Os diagramas de Ishikawa elaborados para os problemas abordados são representados nas figuras 5 e 6 .

Figura 5 - Diagrama de Ishikawa do problema atraso da prescrição.

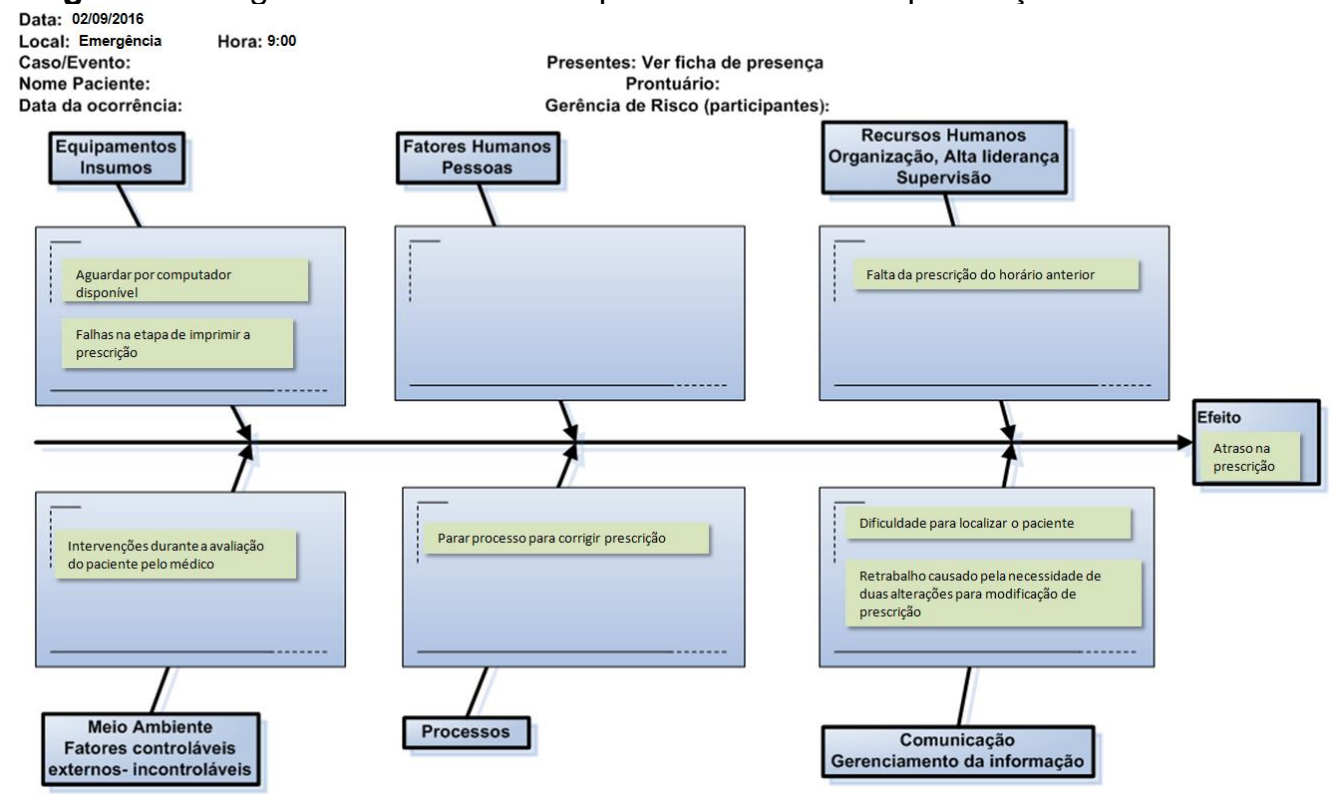

A aplicação do método RCA resultou em 15 ações de melhoria propostas, as quais foram classificadas com uma média de 4,2 para o critério dificuldade de implementação da ação e 5,4 para possibilidade de replicação entre as unidades do hospital. A média do indicador Prioridade é 26,7. As ações resultantes, bem como suas avaliações, são apresentadas no quadro 6. No quadro 7 são apresentadas as 
causas potenciais identificadas para os problemas abordados, bem como as respectivas ações preventivas propostas para eliminá-las.

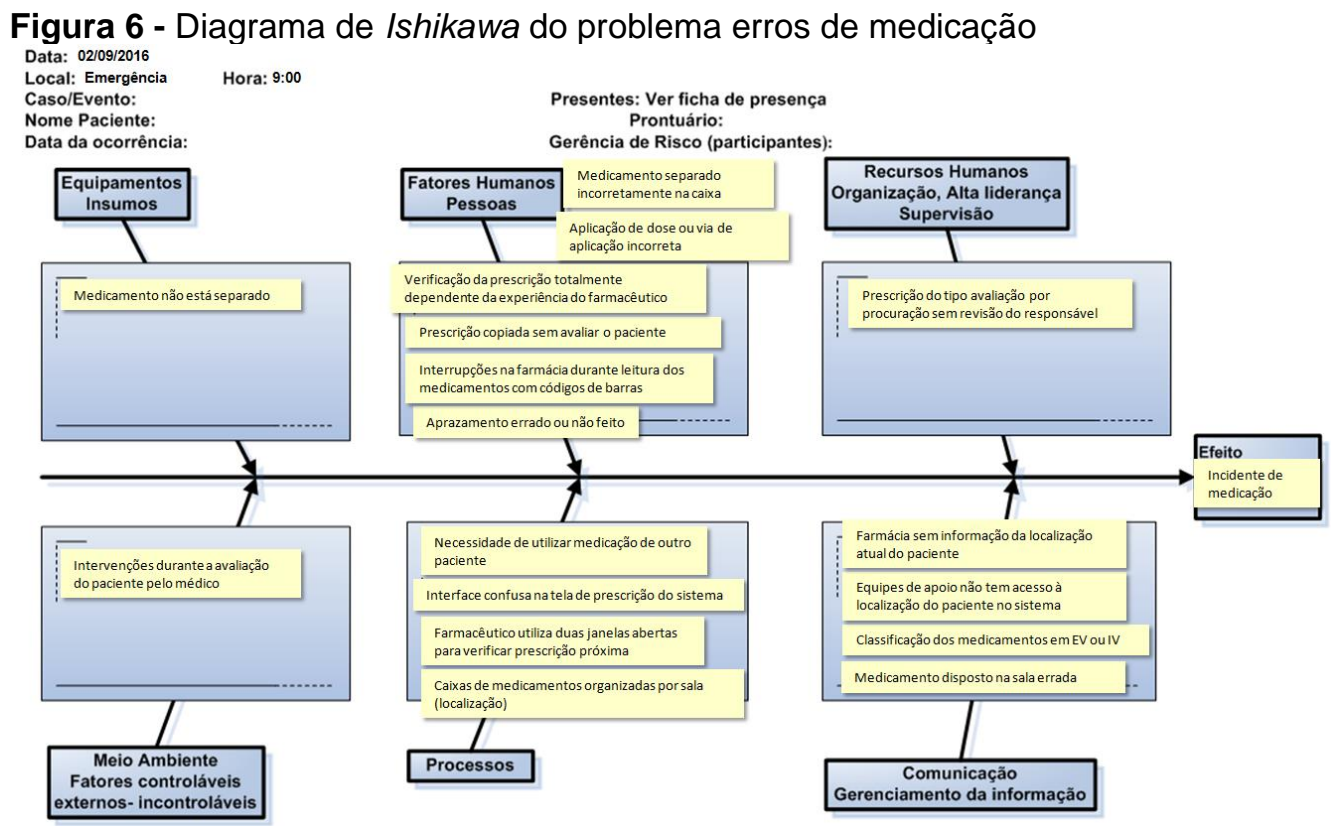

Quadro 6 - Ações de melhoria resultantes da aplicação da metodologia RCA, classificadas de acordo com os critérios de dificuldade de aplicação e replicabilidade

\begin{tabular}{|c|c|c|c|c|}
\hline $\mathbf{N}^{\circ}$ & Ação Preventiva & Dificuldade & Replicação & Prioridade \\
\hline 1 & $\begin{array}{l}\text { Viabilizar o cadastro de impressoras alternativas vinculado ao } \\
\text { usuário, permitindo acessar diferentes impressoras através de } \\
\text { qualquer dispositivo. }\end{array}$ & 3 & 1 & 3 \\
\hline 2 & $\begin{array}{l}\text { Reforçar medidas para aumentar o giro de leitos para a } \\
\text { emergência. }\end{array}$ & 3 & 1 & 3 \\
\hline 3 & $\begin{array}{l}\text { Disponibilizar para SADT apenas a informação de localização } \\
\text { do paciente ou de local e equipe. }\end{array}$ & 1 & 1 & 1 \\
\hline 4 & Desvincular os nomes das equipes dos nomes dos locais. & 9 & 1 & 9 \\
\hline 5 & $\begin{array}{l}\text { Implementar alertas visuais indicando doses absurdas na } \\
\text { prescrição. }\end{array}$ & 1 & 9 & 9 \\
\hline 6 & $\begin{array}{l}\text { Reestruturação dos treinamentos de acordo com as práticas } \\
\text { atuais e setoriais da emergência, elaborados com participação } \\
\text { de profissionais do setor. }\end{array}$ & 9 & 9 & 81 \\
\hline 7 & $\begin{array}{l}\text { Estruturar a equipe da farmácia com dedicação por atividades, } \\
\text { pessoas diferentes separando medicamento e atendendo } \\
\text { demandas. }\end{array}$ & 1 & 3 & 3 \\
\hline 8 & Reduzir número de pacientes por técnico. & 3 & 1 & 3 \\
\hline 9 & $\begin{array}{l}\text { Avaliar a possibilidade de uma pessoa dedicada para o } \\
\text { aprazamento. }\end{array}$ & 3 & 9 & 27 \\
\hline 10 & Unificar o cadastro de via de aplicação. & 9 & 9 & 81 \\
\hline 11 & Revisar interface para prescrição próxima. & 9 & 9 & 81 \\
\hline 12 & Lista de emergência pré-definida para prescrição de urgência. & 9 & 9 & 81 \\
\hline 13 & $\begin{array}{l}\text { Permitir a opção de carregar modificação da prescrição } \\
\text { anterior para a seguinte, em uma interface entre prescrição } \\
\text { vigente e próxima. }\end{array}$ & 1 & 9 & 9 \\
\hline 14 & $\begin{array}{l}\text { Caixa de checagem de dose de ataque para não transmitir } \\
\text { doses únicas para a seguinte. }\end{array}$ & 1 & 9 & 9 \\
\hline 15 & Disponibilizar modelos de prescrição padrão dos serviços. & 1 & 1 & 1 \\
\hline
\end{tabular}


Quadro 7 - Problemas associados às potenciais causas e respectivas ações preventivas

\begin{tabular}{|l|l|c|}
\hline \multicolumn{1}{|c|}{ Problema } & \multicolumn{1}{|c|}{ Causa Potencial } & Ação Preventiva \\
\hline Atraso na prescrição & Falhas na etapa de imprimir a prescrição & 1 \\
\hline Atraso na prescrição & Falta de prescrição do horário anterior & 2 \\
\hline Incidente de medicação & Medicamento separado incorretamente na caixa & 3 \\
\hline Incidente de medicação & Medicamento separado incorretamente na caixa & 4 \\
\hline Incidente de medicação & $\begin{array}{l}\text { Verificação da prescrição totalmente dependente } \\
\text { da experiência e atenção do farmacêutico }\end{array}$ & 5 \\
\hline Incidente de medicação & Dose incorreta ou via de aplicação incorreta & 6 \\
\hline Incidente de medicação & $\begin{array}{l}\text { Interrupções na farmácia durante leitura dos } \\
\text { medicamentos com códigos de barras }\end{array}$ & 7 \\
\hline Incidente de medicação & Aprazamento errado ou não feito & 8 \\
\hline Incidente de medicação & Aprazamento errado ou não feito & 9 \\
\hline Incidente de medicação & Classificação de medicamentos em EV ou IV & 10 \\
\hline Incidente de medicação & $\begin{array}{l}\text { Farmacêutico utiliza duas janelas para prescrição } \\
\text { próxima }\end{array}$ & 11 \\
\hline Incidente de medicação & Medicamento não está separado & 12 \\
\hline Incidente de medicação & Erros de prescrição & 13 \\
\hline Incidente de medicação & Erros de prescrição & 14 \\
\hline Incidente de medicação & Erros de prescrição & 15 \\
\hline
\end{tabular}

Os quatro profissionais envolvidos na aplicação da RCA responderam a entrevista sobre o método, sendo que dois deles tinham conhecimento prévio da metodologia, por terem participado de investigações conduzidas no hospital. Nenhum dos participantes considerou a metodologia complexa quanto ao aprendizado ou a aplicação, sendo destacado por um deles que ela pode ser considerada complicada no sentido de ser completa e abrangente, mas não em relação a dificuldades envolvidas. Poucas dificuldades foram relatadas para aplicação do RCA, em especial um dos participantes alegou que encontrou maior dificuldade na aplicação dos 5 Porquês. Dentre os pontos positivos, três dos participantes citaram a integração entre as áreas envolvidas, que possibilita melhor compreensão do processo pelo ponto de vista das áreas correlatas, aumentando a empatia entre os participantes. Um dos entrevistados citou a dificuldade de se desvencilhar das atividades de rotina para pensar em melhorias, destacando que esses momentos deveriam ocorrer com maior frequência. Dois participantes alegaram que outras iniciativas já haviam resultado em respostas semelhantes, inferindo, por esse motivo, que talvez fosse possível chegar aos mesmos resultados obtidos sem o uso da metodologia RCA. Três dos entrevistados concordaram que o tempo utilizado para execução do trabalho, um total de quatro horas, foi adequado, enquanto um deles colocou que, devido à complexidade do processo, seria necessário mais tempo para aprofundar as análises, bem como para avaliar o 
impacto das ações sugeridas em outras áreas. Foi unânime a percepção de que a metodologia poderia ser utilizada em outros processos e outros setores do hospital, sendo acrescentado por um participante que uma etapa inicial de integração da equipe de trabalho poderia ajudar a reduzir "desabafos", ocasionados pela vontade dos integrantes exporem problemas com os quais convivem, fora dos momentos dedicados para esse fim. Um dos entrevistados sugeriu que fosse acrescentada à metodologia uma etapa dedicada para a priorização das causas de acordo com o impacto no processo percebido pela equipe, de forma a concentrar os esforços nas atividades com maior impacto.

\subsection{Avaliação dos métodos}

Avaliando-se o resultado das aplicações dos métodos, resumidos no quadro 8, percebe-se que a média dos critérios dificuldade de implementação e possibilidade de replicação entre as unidades foi menor para as ações resultantes do método $A 3$, sinalizando uma maior dificuldade envolvida na implementação desse plano.

Quadro 8 - Resultados dos critérios comparativos dos métodos

\begin{tabular}{|l|c|c|}
\hline \multicolumn{1}{|c|}{ Critério comparativo } & A3 & MĆtodo \\
\hline Número de ações de melhoria propostas & 13 & 15 \\
\hline Dificuldade de implementação das ações (média) & 2,1 & 4,2 \\
\hline Possibilidade de replicação das ações (média) & 3,5 & 5,4 \\
\hline Tempo necessário para aplicação & $4 \mathrm{~h}$ & $4 \mathrm{~h}$ \\
\hline Número de envolvidos na equipe & 4 & 3 \\
\hline Necessidade de capacitação da equipe & Sem capacitação prévia & Sem capacitação prévia \\
\hline
\end{tabular}

Essa diferença pode ser ocasionada pelo fato da equipe diretamente envolvida na elaboração do relatório A3 ser composta apenas por membros provenientes da equipe de enfermagem, enquanto algumas das ações propostas eram referentes a outras áreas de atuação que, apesar de terem fornecido informações para o estudo, não foram consultadas quanto à viabilidade das contramedidas propostas durante a elaboração do relatório. O fato de nenhuma liderança ter participado da equipe também pode ter sido limitante para a análise crítica das ações propostas, pois um líder poderia ter mais informações para indicar a inviabilidade de uma ação, permitindo a reformulação desta pela equipe antes da

Revista Produção Online. Florianópolis, SC, v. 20, n. 1, p. 63-94, 2020 
conclusão do trabalho. $O$ fato do relatório $A 3$ ter sido construído no ambiente de trabalho dos envolvidos, apesar de ter facilitado a visualização do processo e das falhas relatadas, pode ter sido prejudicial ao permitir constantes interrupções aos participantes, que frequentemente eram requeridos para outras atividades durante as reuniões do projeto. Também é importante destacar que abordagem A3 foi aplicada de forma pontual em um contexto externo à filosofia Lean, que não está aderida à cultura da instituição. Kymsey (2010) afirma que no contexto da filosofia Lean o processo de solução de problemas é uma "segunda natureza" dos funcionários.

As experiências anteriores em iniciativas de melhoria por parte dos participantes da RCA podem ter auxiliado na sugestão de ações com menor dificuldade de implementação e maior possibilidade de replicação entre as unidades, refletindo nas maiores médias das avaliações desse método. Também cabe destacar o maior número de envolvidos, com participação direta de representantes de todas as áreas e de uma liderança na equipe do projeto RCA, que permitiu a avaliação do processo pelo ponto de vista multidisciplinar, resultando em ações mais específicas dos setores envolvidos, o que pode justificar o maior número de ações propostas obtido com essa metodologia.

Analisando-se as 28 ações resultantes dos dois métodos, verifica-se que apenas quatro delas compartilham algum objetivo, ainda que exposto de forma diferente, sendo todas as demais singulares. As ações 'disponibilizar para SADT apenas a informação de localização do paciente ou de local e equipe' e 'unificar listas das equipes de acordo com a localização física do paciente', propostas respectivamente no $\mathrm{RCA}$ e no $\mathrm{A} 3$, compartilham o objetivo de impedir erros no direcionamento dos medicamentos, pois a informação fornecida é vinculada ao nome da equipe, o que não reflete a localização real do paciente, que pode ter sido transferido desde o último registro, causando que a farmácia direcione o medicamento do paciente para um local onde ele não está mais. Também as ações 'reduzir número de pacientes por técnico', resultante do RCA, e 'adequar cálculo de número de funcionários da enfermagem de acordo com o número real de pacientes', proposta no $A 3$, objetivam reduzir a sobrecarga dos técnicos de enfermagem, promovendo melhora na qualidade do atendimento ao paciente, ressaltando que a premissa que originou a ação proveniente do método A3 foi considerada incoerente 
pelos responsáveis pela avaliação das ações, o que resultou em diferentes pontuações entre essas medidas. O fato de objetivos serem compartilhados por diferentes ações pode ser interpretado como uma ênfase nesses aspectos, servindo de indicativo para que a instituição dedique atenção prioritária para eles. Apesar de ambos os métodos basearem-se na análise de causas para definição das ações de melhoria, mesmo nas ações que compartilham o mesmo objetivo não é possível traçar um paralelo entre as causas potenciais identificadas através do A3 e do RCA, visto que cada equipe teve uma abordagem diferente na interpretação e aprofundamento dos problemas avaliados, resultando em causas descritas em diferentes níveis de detalhamento.

O tempo utilizado para a aplicação foi o mesmo em ambos os métodos, sendo considerado adequado pela maioria dos participantes consultados, indicando que o tempo necessário seja semelhante para essas abordagens. Nas duas aplicações as análises iniciaram sem capacitação prévia das equipes, orientadas apenas pelo autor do estudo durante o projeto, que ainda assim não reportaram dificuldades significativas para compreensão ou aplicação dos métodos, sinalizando que a necessidade de capacitação seja equivalente para o RCA e o A3, ainda que a experiência anterior de alguns membros da equipe do método RCA possa ter facilitado a execução do trabalho. Durante a realização do estudo, diversas iniciativas de melhoria estavam em execução paralela na instituição, algumas abordando etapas do mesmo processo estudado, sendo possível que o eventual acesso a informações dessas iniciativas por parte de membros das equipes tenha influenciado os resultados de ambas as aplicações.

Os resultados obtidos sugerem que, nas condições do estudo, os métodos abordados foram adequados para o contexto avaliado, resultando em um número de ações de melhoria propostas considerado satisfatório pela instituição, as quais em média são de implementação viável e replicáveis, sendo o tempo e a necessidade de capacitação prévia, para ambos os métodos, coerentes para a ambiente avaliado. Uma limitação do estudo foi a diferença na formação da equipe de trabalho das duas metodologias abordadas, que não contou com a mesma diversidade de representantes das áreas nos dois casos. Essa diferença foi atenuada pela vasta experiência dos membros da equipe no processo, os quais possuíam perfis similares, manifestado na vontade de participar de iniciativas para melhoria do 
trabalho na unidade. Uma sugestão pra próximos estudos seria avaliar os efeitos da multidisciplinaridade da equipe nos métodos estudados. Futuras pesquisas também podem avaliar a influência da tomada de decisão clínica, ao priorizar a prescrição de novos pacientes na unidade de emergência, no atraso de prescrição.

\section{CONCLUSÕES}

Diante da necessidade da melhoria contínua para o aprimoramento da qualidade dos setores assistenciais da saúde, o presente trabalho propôs a análise de duas das metodologias de soluções de problemas mais utilizadas, o A3 e o RCA, com o intuito de indicar a abordagem mais adequada no contexto de uma emergência hospitalar. Para esse fim, as ações de melhoria propostas foram classificadas de acordo com os critérios de dificuldade de implementação e a possibilidade de replicação da ação entre as unidades do hospital, sendo os valores dos dois critérios multiplicados para gerar um indicador denominado Prioridade, utilizado para avaliar a atratividade das ações resultantes dos métodos. Também foram avaliados o tempo necessário para aplicação das metodologias, o número de envolvidos, a necessidade de capacitação e o número total de oportunidade de melhoria identificadas.

No contexto avaliado os métodos se demonstraram adequados, pois resultaram em um número satisfatório, para instituição, de ações de melhoria sugeridas, as quais tiveram, em média, avaliações coesas nos critérios dificuldade de implementação e abrangência entre as unidades. O tempo necessário para a aplicação e a capacitação dos envolvidos foram considerados equivalentes para ambos os métodos; uma limitação do estudo foi o número de envolvidos nas equipes, que foi menor para a aplicação do método $A 3$, assim como não contou com a mesma multidisciplinaridade presente na equipe que trabalhou com o método RCA. Todos os consultados alegaram ver possibilidades de aplicar ambos os métodos em outras áreas e processos do hospital, demonstrando satisfação com esse tipo de iniciativa de melhoria contínua.

\section{REFERÊNCIAS}

BAGIAN, JAMES P. et al. The Veterans Affairs root cause analysis system in action. The Joint Commission journal on quality improvement, v. 28, n. 10, p. 531-545, 2002. 
https://doi.org/10.1016/S1070-3241(02)28057-8

BHUIYAN, NADIA; BAGHEL, AMIT. An overview of continuous improvement: from the past to the present. Management decision, v. 43, n. 5, p. 761-771, 2005.

https://doi.org/10.1108/00251740510597761

CARD, ALAN J. The problem with '5 whys'. BMJ Qual Saf, p. bmjqs-2016-005849, 2016. https://doi.org/10.1136/bmjgs-2016-005849

DOGGETT, A. MARK. Root cause analysis: a framework for tool selection. The Quality

Management Journal, v. 12, n. 4, p. 34, 2005.

https://doi.org/10.1080/10686967.2005.11919269

FINLOW-BATES, TERRY; VISSER, BERT; FINLOW-BATES, CHRISTINE. An integrated approach to problem solving: linking KT, TQM and RCA to TPM. The TQM Magazine, v. 12, n. 4, p. 284-289, 2000.

https://doi.org/10.1108/09544780010325912

FONSECA, AUGUSTO VM; MIYAKE, DARIO IKUO. Uma análise sobre o Ciclo PDCA como um método para solução de problemas da qualidade. In: ENCONTRO NACIONAL DE ENGENHARIA DE PRODUÇÃO, 26., 2006. [Anais...] p 1-9, Fortaleza, CE, 2006.

HAMMER, MICHAEL. Process management and the future of Six Sigma. MIT Sloan management review, v. 43, n. 2, p. 26, 2002.

HARTEL, MAXIMILIAN J. et al. High incidence of medication documentation errors in a Swiss university hospital due to the handwritten prescription process. BMC health services research, v. 11, n. 1, p. 199, 2011.https://doi.org/10.1186/1472-6963-11-199

IEDEMA, RODERICK AREN MICHAEL et al. Turning the medical gaze in upon itself: root cause analysis and the investigation of clinical error. Social science \& medicine, v. 62, n. 7, p. 16051615, 2006. https://doi.org/10.1016/j.socscimed.2005.08.049

JIMMERSON, CINDY; WEBER, DOROTHY; SOBEK, DURWARD K. Reducing waste and errors: piloting lean principles at Intermountain Healthcare. Joint Commission Journal on Quality and Patient Safety, v. 31, n. 5, p. 249-257, 2005. https://doi.org/10.1016/S1553-7250(05)31032-4

KIMSEY, DIANE B. Lean methodology in health care. AORN journal, v. 92, n. 1, p. 53-60, 2010. https://doi.org/10.1016/j.aorn.2010.01.015

PMid:20619772

KOPPEL, ROSS et al. Role of computerized physician order entry systems in facilitating medication errors. Jama, v. 293, n. 10, p. 1197-1203, 2005.

https://doi.org/10.1001/jama.293.10.1197

LIVINGSTON, A. D.; JACKSON, G.; PRIESTLEY, K. Root causes analysis: Literature review. HSE Contract Research Report, 2001.

LYNCH, DONALD P.; BERTOLINO, SUZANNE; CLOUTIER, ELAINE. How to scope DMAIC projects. Quality progress, v. 36, n. 1, p. 37-41, 2003.

MAST, JEROEN; LOKKERBOL, JORAN. An analysis of the Six Sigma DMAIC method from the perspective of problem solving. International Journal of Production Economics, v. 139, n. 2, p. 604-614, 2012. https://doi.org/10.1016/i.jpe.2012.05.035

NEILY, JULIA et al. Using aggregate root cause analysis to improve patient safety. Joint 
Commission Journal on Quality and Patient Safety, v. 29, n. 8, p. 434-439, 2003. https://doi.org/10.1016/S1549-3741(03)29052-3

NOVARETTI, MARCIA CRISTINA ZAGO. Aplicação da análise causa raiz como ferramenta na gestão de segurança hospitalar. Revista de Administração da Universidade Federal de Santa Maria, v. 7, n. 3, 2014. https://doi.org/10.5902/1983465916272

OKES, DUKE. Improve your root cause analysis. Manufacturing Engineering, v. 134, n. 3, p. 171-178, 2005.

PAIM, JAIRNILSON et al. Saúde no Brasil 1: o sistema de saúde brasileiro: história, avanços e desafios. Veja, v. 6736, n. 11, p. 60054-8, 2012.

PASIN, SIMONE S. Análise do preparo e administração de medicamentos: priorização dos problemas e planejamento de melhorias na perspectiva lean. Artigo (Especialização em Gestão da Produção) - Universidade Federal do Rio Grande do Sul, Porto Alegre, RS, 2015.

ROONEY, JAMES J.; HEUVEL, LEE N. VANDEN. Root cause analysis for beginners. Quality progress, v. 37, n. 7, p. 45, 2004.

SHOOK, JOHN. Gerenciando para o aprendizado. São Paulo: Lean Institute Brasil, 2008.

SHOOK, JOHN. Toyota's secret. MIT Sloan management review, v. 50, n. 4, p. 30, 2009.

SCHROEDER, ROGER G. et al. Six Sigma: Definition and underlying theory. Journal of operations Management, v. 26, n. 4, p. 536-554, 2008.

https://doi.org/10.1016/i.jom.2007.06.007

SOBEK II, DURWARD K.; JIMMERSON, CINDY. A3 reports: Tool for organizational transformation. In: IIE ANNUAL CONFERENCE. [Proceedings...]. Institute of Industrial and Systems Engineers (IISE), 2006. p. 1.

SOBEK II, DURWARD K.; SMALLEY, ART. Understanding A3 thinking: a critical component of Toyota's PDCA management system. CRC Press, 2011.

https://doi.org/10.4324/9781439814055

TEIXEIRA, THALYTA CARDOSO ALUX; CASSIANI, SILVIA HELENA DE BORTOLI. Análise de causa raiz: avaliação de erros de medicação em um hospital universitário. Revista da Escola de Enfermagem da USP, v. 44, n. 1, 2010. https://doi.org/10.1590/S0080-62342010000100020

TEIXEIRA, THALYTA CARDOSO ALUX; CASSIANI, SILVIA HELENA DE BORTOLI. Análise de causa raiz de acidentes por quedas e erros de medicação em hospital. Acta Paulista de Enfermagem, v. 27, n. 2, 2014. https://doi.org/10.1590/1982-0194201400019

TULLY, MARY P. et al. The causes of and factors associated with prescribing errors in hospital inpatients. Drug safety, v. 32, n. 10, p. 819-836, 2009.

https://doi.org/10.2165/11316560-000000000-00000

WU, ALBERT W.; LIPSHUTZ, ANGELA KM; PRONOVOST, PETER J. Effectiveness and efficiency of root cause analysis in medicine. Jama, v. 299, n. 6, p. 685-687, 2008.

https://doi.org/10.1001/jama.299.6.685

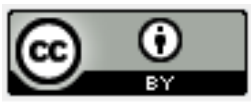

Artigo recebido em: 24/05/2018 e aceito para publicação em: 04/03/2020

DOI: http://dx.doi.org/10.14488/1676-1901.v20i1.3258

Revista Produção Online. Florianópolis, SC, v. 20, n. 1, p. 63-94, 2020 